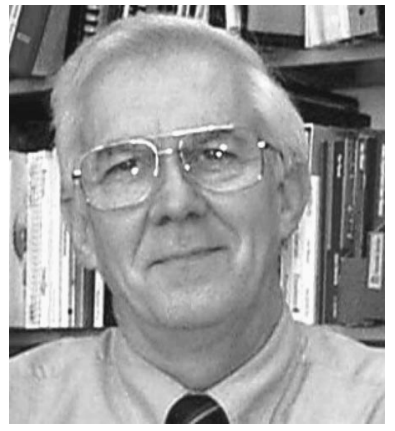

\section{The First Modern Engineer}

On a vacation to the West of Ireland last summer, my wife and I took a ferry out to the Aran Isles that sit at the mouth of Galway Bay. We were going to visit a Stone Age fort, Dun Aenghus, that was built at the edge of a cliff on the island of Inishmore. I had a portable Magellan Global Positioning System (GPS) unit that was lent to me by my editorial assistant for this journal, Maria Cordell. After playing with it in Atlanta, I took it to Ennis, Ireland, and on some of our jaunts around the Irish countryside, including the ferry ride. I was admiring how little the bearing of the ferry wavered when its captain wandered to the back and we struck up a conversation. The passage at one time could be quite a great challenge, he told me. But now with this technology, represented by this little unit in my hand, it was not difficult in all but the worst weather. We talked until the boat docked; his first mate had taken the ferry over to the island and there was no need for him to butt in. For some, the novelty of this gadget might wear off after a few days, but I must say that I was continually amazed by it and the technology that it represents. There are other devices for determining one's place on the face of the earth, but none are as universal, or should I say, global as GPS. Its predecessor was the chronometer.

One of the most fascinating books of the past few years is Longitude, The True Story of a Lone Genius Who Solved the Greatest Scientific Problem of His Time by Dava Sobel (Penguin, 1995). It describes the search for a solution to the problem of determining the location of a ship at sea. While detailing some of the more exotic proposals (the yelp of a wounded dog caused by dipping its bandage, kept at port, sprinkled with a "powder of sympathy" every day at noon), the book describes the efforts of John Harrison, an English clockmaker, to perfect an accurate chronometer.

For England, a seafaring nation, the problem was so pressing that a prize committee was set up. They sought the advice of Newton and Halley. Although Newton suggested an accurate timepiece as a possible solution, he favored more elaborate astronomical methods. On July 14, 1714, the Longitude Act was issued. The first prize of $£ 20,000$ would be awarded to the first person to develop a method that would determine the longitude to an accuracy of a half of a degree of longitude of a great circle. At the equator this is equivalent to an inaccuracy in distance of 30 nautical miles. Provided there is sufficient visibility and a navigator can measure the transit of stars, it is also equivalent to maintaining the local time to within three seconds a day.

The book describes the trials and tribulations that Harrison suffered in the course of perfecting his invention. A self-educated man, Harrison mastered Newton's Principia and a physics textbook by Nicholas Saunderson of Cambridge. He had to deal not only with the difficulties of bending metal to his wishes, both literally and figuratively, he also had to deal with political interference of the most outrageous sort. And it was a slow process. As Sobel notes:

Rome wasn't built in a day, they say. Even a small part of Rome, the Sistine Chapel, took eight years to construct, plus another eleven years to decorate, with Michelangelo sprawled atop his scaffolding from 1508 to 1512, frescoing scenes from the Old Testament on the ceiling. Fourteen years passed from the conception to the casting of the Statue of Liberty. The carving of the Mount Rushmore Monument likewise spanned a period of fourteen years. The Suez and Panama Canals each took about ten years to excavate, and it was arguably ten years from the decision to put a man on the moon to the successful landing of the Apollo lunar module.

It took John Harrison nineteen years to build $\mathrm{H}-3$.

Historians and biographers cannot explain why Harrison-who turned out a turret clock in two years flat when he had scant experience to guide him, and who made two revolutionary sea clocks within nine yearsshould have lingered so long in the workshop with H-3. No one suggests that the workaholic Harrison dallied or became distracted. Indeed, there is evidence that he did nothing but work on $\mathrm{H}-3$, almost to the detriment of his health and family, since the project kept 
him from pursuing most other gainful employment. Although he took on a few mundane clockmaking jobs to make ends meet, his recorded income during this period seems to have come entirely from the Board of Longitude, which granted him several extensions on his deadline and five payments of $£ 500$ each.

Had the author consulted an engineer she might have gotten an explanation. If you look back on the history of precision engineering, it is possible to make a case for the work of John Harrison as the First Modern Engineer. The Longitude committee had, in the establishment of its First Prize, required the winner to engineer a device with an accuracy of 3 seconds a day or 35 parts per million. Was there any technological enterprise up to that time that came close to these demands?

Consider the obstacles that Harrison faced. He had to invent the mechanisms that compensated for, or isolated against, environmental changes (temperature, motion, etc.). Just as important, Harrison had to test all of the changes he made against the only standard he had available, the movement of the stars, in a land not noted for exceedingly clement weather. One or two days would not do, either. Long term drifts from environmental factors had to be taken into account. And when you are establishing the first mechanical standards for time, there is no such thing as an accelerated test. We should honor Harrison not only for his great ingenuity, but also for his patience!
Before he set to work to win the Longitude Prize Harrison had already invented a new escapement mechanism and a bimetallic temperature compensator for clocks. He later refined the compensator into a bimetallic strip of the type that we still use in our thermostats. He also either invented, or refined, the caged ball races that are the heart of ball bearings. Finally, to reduce friction in the mechanisms, he introduced the jeweled bearing. It was his successive development of techniques that eventually permitted him to conquer the problem.

Anyone who has visited the Royal Maritime Museum in Greenwich comes away with a respect for this otherwise ordinary man, who by dint of continued refinements and clever solutions to complex problems, solved the most difficult problem of his time. For me he merits the title of the First Modern Engineer. In his invention of the chronometer he employed mechanics and material science, developed by others, in a rudimentary form to achieve phenomenal precision.

The first time I used a handheld GPS unit I gained a new sense of where I was in this universe. The grid that I had regarded for so many years on the maps of the world became a part of my mental landscape. To me the display screen on the unit that shows the location and signal strengths of the current GPS satellites provides a sense of awe. I wonder what Mr. Harrison would make of the technology that has, on a worldwide basis, supplanted his great advance.
Donald C. O'Shea Editor 